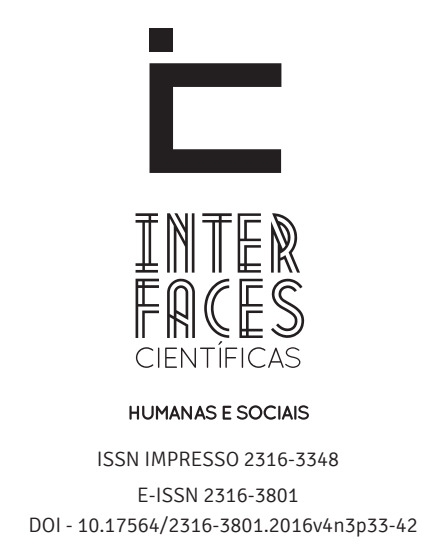

\title{
O TRIBUNAL DO FEICEBUQUI E A PÁGINA ABERTA PARA A OPRESSÃO
}

THE COURT OF FEICEBUQUI AND THE PAGE OPEN FOR OPPRESSION

EL TRIBUNAL DE FEICEBUQUU Y LA PÁGINA ABIERTA PARA LA OPRESIÓN

\section{RESUMO}

A partir de uma performance realizada nos festejos de lemanjá, em Salvador, e com base nos estudos Pós-Coloniais, Queer e Subalternos, os autores analisam, de forma interdisciplinar, como a rede social Facebook vem se tornando um tribunal inquisitório contemporâneo.
Duda Woyda²

\section{PALAVRAS-CHAVE}

Performance. Redes sociais. Teoria queer. 


\section{ABSTRACT}

From a performance held in the celebrations of Yemanja, Salvador, and based on Post-Colonial Studies, Queer and Subaltern, the authors analyze , in an interdisciplinary way, as the social network Facebook has become a contemporary inquisitorial court.

\section{RESUMEN}

A partir de una performance en las celebraciones de Yemanjá, Salvador, y con base en los estudios Post-Coloniales, Queer y Subalternos, los autores analizan, de manera interdisciplinaria, como la red social Facebook se ha convertido en un tribunal inquisitorial contemporáneo.

\section{KEYWORDS}

Performance. Social networks. Queer theory.

\section{PALABRAS-CLAVE}

Rendimiento. Redes sociales. Teoría queer. 


\section{SOBRE COMO AS IDEIAS POUSAM OU À GUISA DE INTRODUÇ̃̃O}

Este trabalho, fruto das discussões realizadas no CuS - Grupo de Pesquisa em Cultura e Sexualidades, da UFBA e da ATeliê voadOR Companhia de Teatro, tem o intuito de pensar sobre algumas inquietações que vem sendo expostas sobre a utilização do Facebook e, para isso, foi imprescindível dialogar com referenciais teóricos como Juan Carlos Tedesco (2004), Nelson Preto (2006), Pierre Lévy $(1999,1993)$ em especial para que pudéssemos refletir com mais propriedade a problemática aqui abordada trazendo para o debate dúvidas, questionamentos, oposições, mas também posições afirmativas que poderão demonstrar que o uso do Facebook, quando bem conduzido, pode propiciar o interesse e a potência intercultural.

Quando pensávamos em escrever sobre o Facebook, confessamos, ainda não tínhamos definido sobre o recorte que escreveríamos. Tínhamos uma dezena de ideias, que é como normalmente procedemos, o tal brainstorm, e dessas ideias algumas linhas mais descritivas sobre o formato do capítulo. Nada mais. 0 mais pulsante para nós era o reconhecimento de que o Facebook teria se tornado um verdadeiro tribunal inquisitório. Tom Zé já teria percebido esse caráter quando cantou a letra de "Tribunal do Feicebuqui", numa auto-sátira poético-crítica e cômica do Brasil contemporâneo, que aludia ao faturamento de R\$ $80.000,00$ (oitenta mil reais) que recebeu da Coca-Cola pela narração do comercial "A Copa do Mundo" 2 . A propaganda trazia "as costumeiras imagens festivas do Brasil, emolduradas por um discurso inclusivo que associava o País de todo o mundo ao esporte de todo mundo e à bebida de todo mundo. A gritaria contra o artista foi notável: ele foi julgado e condenado nas redes sociais como 'vendido'” (Alves-Bezerra, 2014).

\footnotetext{
1. Letra de (Marcelo Segreto / Gustavo Galo / Tatá Aeroplano / Emicida). 2. https://www.youtube.com/watch?v=ZhALrgpkq38.
}

Em ato seguido, em 2013, Tom Zé, um dos nomes mais inquietos da Contracultura brasileira, tomou para si a acusação da qual foi alvo e doou o cachê para a Sociedade Lítero-Musical 25 de Dezembro, de Irará, sua cidade natal, na Bahia (BA) e colocou-se como réu no Tribunal, ao mesmo tempo em que assumia o papel que alguns artistas se outorgam em tempos difíceis, o de expressar-se de maneira pública e singular sobre o acontecido. Tom Zé, em sua página do Facebook escreveu:

“SOBRE O ANÚNCIO DA COCA-COLA

Pois é, pessoal, estou preocupado. Eu dou importância à opinião de vocês. Essa alegria sempre me acompanhou.

Quando o anúncio saiu na tv, imaginei que até as opiniões contrárias eram uma espécie de comemoração por eu aparecer com status de locutor de uma propaganda grande. Mas agora, quando perco o sono por causa do assunto... não, agora eu estou preocupado! 0 apoio de vocês sempre foi uma base de sustento. Será que uma alegria nascida do privilégio de até hoje, aos 76, ter vivido dessa profissão de músico e cantor, me fez pensar que eu poderia afrontar essa sustentação?

É curioso que quando fui consultado sobre o anúncio nem pensei nessa probabilidade. No ano passado meu disco fora patrocinado pela Natura e como eu nunca tinha recebido patrocínio desse tipo - nem de nenhum outro - , cara, eu me senti como um artista levado em conta!

Para profissionais de meu tipo as gravadoras são agora inalcançáveis. A Trama, de João Marcello Bôscoli, me deu grande apoio nos anos 90 e até Estudando o Pagode, em 2004. Mas em Danç-Êh-Sá”, já dividimos as responsabilidades. Em 2008 Estudando a bossa foi muito ajudado pela Biscoito Fino; Agradeço, mas ficou difícil continuar lá. No ano passado o apoio da Natura me deu tanta confianca pessoal que ousei fazer o Tropicália Lixo Lógico. No lançamento de Danç-Êh-Sá, em 2005, o resultado foi de extremos. A gravadora francesa teve um ódio tão grande do disco que quase perco até a amizade de Henri Laurence, que lá me lançava pela Sony. Nos 
E.U.A. houve comentários apaixonados na crítica, mas Yale Evelev recusou o disco na Luaka Bop. Logo a seguir a mesma Luaka Bop me respondeu com entusiasmo ao Estudando a bossa de 2008 e depois lançou o super set box de vinis com os 3 Estudando..

E o ... Lixo Lógico recuperou também a amizade de Henri Laurence.

Toda essa dança de lançamentos e esse céu-e-inferno

com os editores-lançadores é própria desse setor onde não devo nem quero relaxar o arco-tenso-da-ousadia. Mas nos dias atuais vivemos a era da internet $\mathrm{e}$ a venda de disco passou a ter um peso insignificante. Já o papel desses lançamentos, em termos de divulgação, é muito eficiente.

Voltemos ao presente. Atualmente sinto paixão pela retomada do projeto dos instrumentos experimentais de 1972. Com a eficiente colaboração do engenheiro Marcelo Blanck, começamos a desenvolver alguma tecnologia, mas com recursos parcos, insuficientes. Os resultados estão nos animando muito. Aí entrou o anúncio da Coca-Cola que, mesmo sem ela saber patrocinaria boa parte da pesquisa.

Será que o uso dos recurss obtidos com o anúncio muda a avaliação de vocês?

Madrugada de sexta, 8 de março, 6h22. tom zé" (https://www.facebook.com/tomze/ posts/10151297893292066. 30/12/2015) buqui:

E, também, na música citada "Tribunal do Feice-

Baixou o tom

Baba baby

Bebe e baba

Velho babão

Tom Zé bundão

Baixou o tom

Baba baby

Bebe e baba

Mané babão

Seu americanizado Quer bancar Carmen Miranda Rebentou o botão da calça Tio Sam baixou em sampa Vendido, vendido, vendido

A preço de banana

Já não olha mais pro samba Tá estudando propaganda
Que decepção

Traidor, mudou de lado Corrompido, mentiroso

Seu sorriso engarrafado

Não ouço mais, eu não gostei do papo Pra mim é o príncipe que virou sapo

Onde já se viu? Refrigerante!

E agora é a Madalena arrependida com conservantes Bruxo, descobrimos seu truque Defenda-se já

No tribunal do Feicebuqui A súplica:

Que é que custava morrer de fome só pra fazer música?

\section{FACEBOOK E O PANÓPTICO VIRTUAL}

Um ano depois, no verão de 2014, trabalhávamos na Pós-Graduação com algumas questões ligadas aos movimentos feminista, gay e negro sob a luz dos Estudos Queer, dos Estudos Pós-Coloniais e dos Estudos Subalternos que, juntos, formam uma forte corrente de crítica ao pensamento hegemônico colonial, aquele em que para que o homem assegure seu domínio é necessário que algo/alguém ocupe a posição de dominado. Butler (2002) questiona a serviço de quê (e a custo de quê) essas normas coloniais se materializam, produzindo sujeitos e corpos inteligíveis e ininteligíveis, relegando os últimos a uma posição de abjetos, sem os quais, paradoxalmente, não se pode produzir os primeiros, chamando a atenção para o fato de que é dessa posição (não como um local físico, mas como um local de discurso) que se pode criticar a norma hegemônica, ou seja, deste local inabitável que é produzido pela mesma norma que o pretende excluir.

Ao se articularem, os saberes subalternos produzem saberes inclusive, ou principalmente, sobre o funcionamento da modernidade, de suas estratégias e também de suas falhas. Unidos pelo sentimento comum de inferioridade, exploração e menos valia, esses subalternos ameaçam, com seus saberes, borrar as linhas, as normas daquilo que se tem como certo. 
No dia 2 de fevereiro, em Salvador, temos uma das mais belas festas populares, a festa de lemanjá. Nesse dia uma mulher oferecia seus pelos pubianos à Rainha do mar, sua ação foi fotografada e amplamente divulgada nas páginas do Facebook.

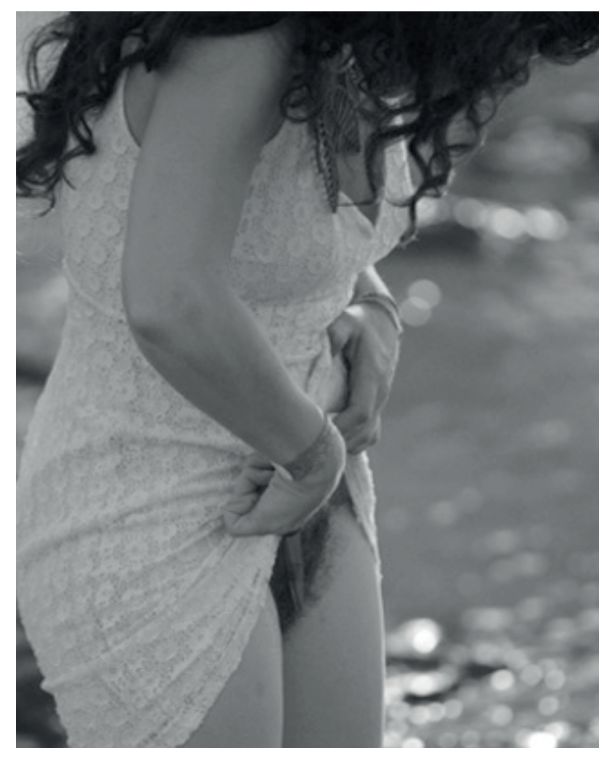

0 que nos impressionou foram as metralhadoras sexistas e machistas disparadas por homens e mulheres contra a ação da foto e, talvez, a razão de seu pedido, um amor. Mais tarde, soubemos, tratar-se-ia de uma performance o que não diminui o impacto das palavras, pois tais atos artísticos “aproximam-se mais, de certa forma, dos atos de vida, prescindindo de maior elaboração estética e contrapondo, de forma mais contundente, o elemento risco/inesperado". (COHEN, GUINSBURG, 1992, 232). A performance nesse caso só ajuda a pensar em como, caso fosse verdade, a sociedade ainda continua a vigiar nossos corpos subalternos, só que agora, com o auxílio do Facebook, arena contemporânea, panóptico pós-moderno da injúria social que quer ferir, envergonhar o outro e a sua diferença. Tudo começa com a seguinte indagação de um facebooker (sic):

\begin{abstract}
A polêmica da semana, pós-Yemanjá, foi a foto da moça que ofertou os pêlos pubianos à deusa do mar, segundo dizem, em busca de um amor. Nada contra pêlos, muito pelo contrário, até porque sou bem farto. Também sou super a favor de quem anda buscando um amor, em tempos de relações tão voláteis. A questão é: Se a moda pega e as mulheres em busca de conquistar o coração da pessoa amada, correrem em massa para cortar seus pêlos púbicos no mar, correremos o risco de confundir sargaço com pentelhos? Exagero à parte, vamos combinar: Mesmo que o mar já esteja cheio de garrafas, espelhos, pneus, cocô, o escambau, jogar pêlos não é fazer também o mar de lixeira?
\end{abstract}

Daí em diante, um mar de injúria³:

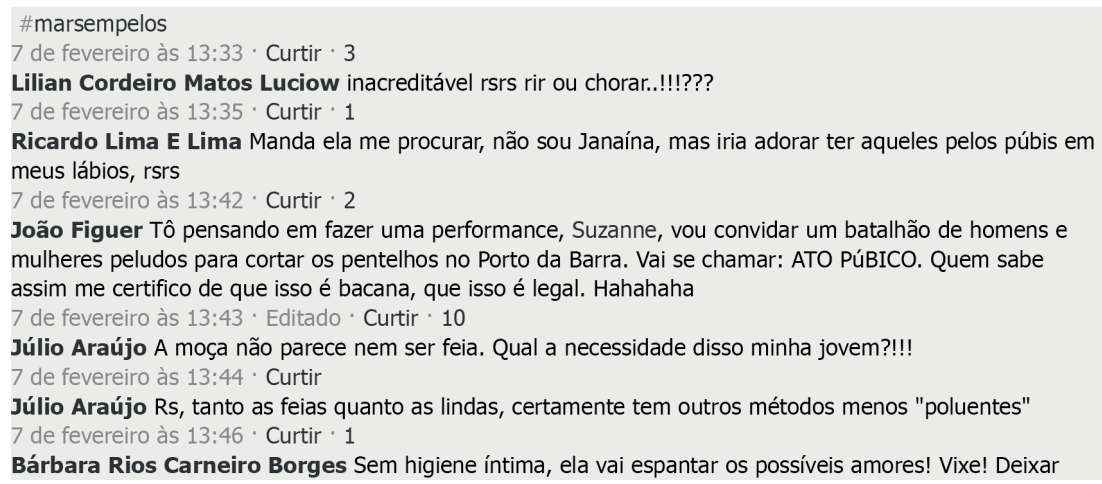

3. Todos os comentários foram acessados em: 10/02/2014 às 22:37. 
para cortar de ano em ano ( a cada 2 de fevereiro). Fazer o que, nê?! Respeitar! Cada um com seus hábitos, suas preferências ...

7 de fevereiro às $13: 49 \cdot$ Curtir $\cdot 2$

Graça Meurray Credo que cena horrível...Essa criatura não podia corta esses pelos em casa e levar pra jogar no mar? Iemanjá deve tá pirada com essa maluca...Coitada!!!kkk

7 de fevereiro às $13: 49 \cdot$ Curtir $\cdot 2$

João Figuer GOsto assim: De quem joga no mar só os pensamentos bons. Acho uma tremenda ignorância dessa moça, mas enfim..

7 de fevereiro às $13: 49 \cdot$ Curtir ' 1

Graça Meurray Vai ficar sem Homem o resto da vida...kkkk

7 de fevereiro às 13:49 ' Curtir · 3

Ari Coelho Mas tava lavadinho e cheirosinho rsss

7 de fevereiro às $13: 52 \cdot$ Curtir $\cdot 2$

Dênisson Padilha Filho Acho que ela confundiu púbicos com públicos..mas tá valendo...

7 de fevereiro às $13: 53 \cdot$ Curtir $\cdot 5$

Rada Rezeda oxe e Yemanja gosta da fruta é? se fosse pentelho de pinto td bem.....mas essa mata de orobó ai.....affff

7 de fevereiro às $14: 11 \cdot$ Curtir $\cdot 5$

Tatiane Camargo Dias Imagino quantos pentelhos ficaram presos nos dentes de Iemanjá.

7 de fevereiro às $14: 14 \cdot$ Curtir $\cdot 2$

Tatiane Camargo Dias Se a moda pega, Iemanjá vai cuspir pentelhos por uma década.

7 de fevereiro às $14: 26 \cdot$ Curtir $\cdot 3$

Samir Matos Tadinha de Janaína.

7 de fevereiro às 14:34 . Curtir ' 1

Jane Urbanetto Essa nunca se depilou na vida...é muito!!!!

7 de fevereiro às 14:41 . Curtir ' 1

Liliana Struminski Jesus.... vou passar longe do Rio Vermelho por um tempol

7 de fevereiro às 14:54 ' Curtir ' 1

Allan Mendonza Acho que já sei o pedido: Um marido dotado.

7 de fevereiro às $14: 55$ - Curtir ' 2

Kohlrausch Gusmão Se ela ainda estiver assim, por mim fica solteira mais um ano...rs...que não tire tudo, mas tem muita coisa ali...rs..ta descendo pelas pernas praticamente!

7 de fevereiro às 15:20 ' Editado ' Curtir

Roberta Abraim Mello I Soube que ela fez promessa para nunca mais faltar alimento para aquela boca....

(não sei se é piada) kkkkkkkkk

7 de fevereiro às 15:39 · Curtir * 6

Fábio Ferreira Iemanjá vai devolver um barbeador... kkkk!!!

\section{QUANDO PENSAMOS À CONTRAPELO}

A experiência subalterna colonial é uma experiência constituinte do sujeito, ou seja, não se reconhece o sujeito nem o sujeito se reconhece de outra maneira; não se é primeiramente sujeito e depois colonizado. A colonização acontece concomitantemente à sujeição, mediante a aceitação das normas e da hierarquia do poder mesmo que constitui em sujeito àquele que interpela.

Em Elogio à Criolidade, Patrick Chamoiseau, Jean Barnabé e Raphaël Confiant descrevem a experiência da criolidade, como será possível observar, uma experiência não tão distante de outras experiências de colonização:
Nossa verdade foi encerrada no mais profundo de nós mesmos, estranha à nossa consciência e à leitura livremente artística do mundo em que vivemos. Somos fundamentalmente marcados pela exterioridade. Isso desde os tempos de outrora até os dias de hoje. Temos visto o mundo através do filtro dos valores ocidentais, e nosso fundamento foi "exotizado" pela visão francesa que tivemos de adotar. Condição terrível a de perceber sua arquitetura interior, seu mundo, os instantes de seus dias, seus valores próprios com o olhar do Outro. Sobredeterminados, do princípio ao fim, em história, em pensamentos, em vida cotidiana, em ideais (mesmo progressistas), em uma armadilha de dependência cultural, de dependência política, de dependência econômica, temos sido deportados de nós mesmos a cada palmo de nossa história escritural. Isso determinou uma escrita pra o Outro, uma escrita emprestada, apoiada nos valores franceses, ou, em todo caso, fora desta terra, e que, apesar de certos aspectos positivos, não fez senão man- 
ter em nossos espíritos a dominação de um outro lugar... De um outro lugar perfeitamente nobre, bem entendido, minério ideal a ser importado, em nome do qual romper a ganga do que nós éramos (1990, p.1).

Nascemos ante uma censura. Não existe aqui um lamento por nascer num mundo já organizado e não poder experimentar o lugar do deus do criacionismo ou do Adão do Gênesis, que a tudo nomeou, mas a denúncia de nascer num mundo hierarquizado e violento no qual se prescreve como cada sujeito deve ser e o que tem de fazer e gostar para que diminua sua defasagem em relação a um modelo preestabelecido. Modelo esse que é homofóbico, racista, sexista, heterossexista, classissita, militarista, cristão e eurocêntrico, "todas ideologias que nascem dos privilégios do novo poder colonial, capitalista, masculinizado, branqueado e heterossexualizado. Não se pode pensar essas ideologias separadas umas das outras. Todas integram a matriz de poder colonial que em nível global ainda existe" (GROSFOGUEL, 2012, p. 343).

Nesse mundo, a experiência de si é censurada por normas e manuais diagnósticos e substituída pela cartilha médico-pedagógica do desenvolvimento “saudável” ideal. Tal prática disciplinar faz do corpo já e a cada momento um

campo político; as relações de poder têm alcance imediato sobre ele; elas o investem, o marcam, o dirigem, o supliciam, sujeitam-no a trabalhos; obrigam-no a cerimônias, exigem-lhe sinais. Este investimento político do corpo está ligado, segundo relações complexas e recíprocas, à sua utilização econômica. [...] Quer dizer que pode haver um "saber" do corpo que não exatamente a ciência de seu funcionamento, e um controle de suas forças que é mais que a capacidade de vencê-las: esse saber e esse controle constituem o que se poderia chamar a tecnologia política do corpo. [...] Trata-se de alguma maneira de uma microfísica do poder posta em jogo pelos aparelhos e instituições, mas cujo campo de validade se coloca de algum modo entre esses grandes funcionamentos e os próprios corpos com sua materialidade e suas forças. Ora, o estudo desta microfísica supõe que o poder nela exercido não seja concebido como uma propriedade, mas como uma estratégia, que seus efeitos de dominação não sejam atribuídos a uma "apropriação", mas a disposições, a manobras, a táticas, a técnicas, a funcionamentos; que se desvende nele antes uma rede de relações sempre tensas, sempre em atividade, que um privilégio que se pudesse deter; que the seja dado como modelo antes a batalha perpétua que o contrato que faz uma cessão ou a conquista que se apodera de um domínio. (FOUCAULT, 2000, p. 26)

A matriz colonial de poder dita as normas e opera as seleções que dividem os sujeitos entre nós e eles, os de dentro e os de fora, as vidas que importam e as que não. No entanto, tal poder se exerce sobre os corpos de maneira silenciosa, constituindo a todos com referência ao modelo linguístico que jamais atingem e jamais conseguem superar; são modelos de inteligibilidade que apontam a sujeição como único caminho para o reconhecimento; uma violência que se impõe pelo sentimento. "Violência suave, insensível, invisível às suas próprias vítimas, que se exerce [...] pelas vias puramente simbólicas da comunicação e do conhecimento, ou, mais precisamente, do desconhecimento, do reconhecimento ou, em última instância, do sentimento". (BOURDIEU, 2007, p. 7-8)

Segundo Bourdieu, o trabalho de construção simbólica de tais normas

não se reduz a uma operação estritamente performativa de nominação que oriente e estruture as representações [...]. O nómos arbitrário que institui as duas classes na objetividade não reveste as aparências de uma lei da natureza [...] senão ao término de uma somatização das relações sociais de dominação: é à custa, e ao final, de um extraordinário trabalho coletivo de socialização difusa e contínua que as identidades distintivas que a arbitrariedade cultural institui se encarnam em habitus claramente diferenciados segundo o princípio de divisão dominante e capazes de perceber o mundo segundo este princípion (2007, p. 33-34, grifos do autor)

Entre todas as relações de colonialidade, é a dominação o traço comum. Marcados pela exterioridade, nossos afetos se constituem sob a constante interpelação da referida matriz a ocuparmos um lugar de reconhecimento e confirmação da norma e, por conseguinte, de nossas inferioridades em relação ao 
modelo por ela estabelecido. A um só tempo, somos também instados a ratificar esse modelo como o único meio viável de existência, condenando todas as demais formas à ininteligibilidade, ao silêncio, à inumanidade e à desimportância, enfim, à abjeção.

A lógica da abjeção orienta o peso, a importância de cada corpo e como eles serão tratados e utilizados. Existem corpos para o trabalho braçal e corpos para o trabalho intelectual, corpos a serem amados e cuidados e outros a serem usados e fodidos. Os corpos falhos, negros, penetráveis, os corpos que são de carne e cuja carne treme ao fluxo de afetos e intensidades que thes percorrem. Eles são força de trabalho, cobaias, vidas a serem colocadas nas linhas de frente numa guerra, trepadas exóticas; não são gente, não são humanos.

Butler, em suas obras dedicadas às questões de gênero e sexualidade, descreve de maneira profunda como se dá a gestão e controle de subjetividades. $\mathrm{Na}$ subseção intitulada Passionate Attachments (Vínculos Apaixonados) em sua obra The Psych Life of Power, Judith Butler demonstra como a ação da norma se dá precocemente na vida de cada ser humano a fim de transformá-lo em sujeito:

o desejo pela sobrevivência, por "ser", é um desejo explorável de maneira difusa; aquele que sustenta a promessa de uma existência continuada se beneficia do desejo por sobrevivência. "Prefiro existir em subordinação que não existir” é uma elaboração deste predicamento (onde o risco de "morte" também é uma possibilidade) (1997, p. 7, tradução nossa).

Tenhamos em mente que, para Butler (1997), os sujeitos são considerados espaços, territórios sobre os quais desejo e poder - inclusive desejo por poder - travam constante disputa. Cada sujeito representa, assim, um tensionamento. Toda repetição que se dá sobre esse terreno é também fratura, pois é uma repetição que não repete: 1) por não alcançar o modelo; e 2) por não se igualar a nenhuma outra. Essa tensão por reproduzir o irreprodutível, gera cópias fraturadas, que a todo instante subvertem a norma, mesmo quando na tentativa de afirmá-la. O poder que confere o status de sujeito e o funda como unidade e individualidade, garantindo uma consistência e uma coerência ou inteligibilidade a uma multiplicidade descontínua aberta para a alteridade, num mesmo ato, pela dupla valência desse sujeito, possibilita a subversão da norma (NAVARRO, 2008).

Os autores com os quais até agora nos pusemos em diálogo tem uma flagrante característica em comum: nenhum deles se remete ao humano como uma essência, como algo que seja anterior ao discurso; pelo contrário, todos falam de uma construção do humano que se dá de maneira diferenciada.

Uma sociedade que se alarga, mas cuja estrutura insiste em não ceder, em não desmoronar, precisa de um novo lugar para confinar a novidade e a diferença, no qual essas serão mantidas sob vigilância. Dos bárbaros aos selvagens, dos colonos às sexualidades não heterossexuais, a desarticulação e a recomposição dos corpos são feitas segundo um modelo que rotula e inferioriza a todos que the excedem.

Mas a batalha é perpétua, as identidades transitórias e contingentes, os ambientes são transitáveis e os corpos são permeáveis. O “Tribunal do Feicebuqui”, espaço do qual escrevemos, é o espaço que reconhecemos como o lugar da alteridade, da potência do Outro e da diferença e não o espaço do patrulhamento e da censura, da vigilância e da punição. Evoé, Tom Zé.

\section{REFERÊNCIAS}

ALVES-BEZERRA. Wilson. http://cultura.estadao. com.br/noticias/musica,tom-ze-um-artista-que-seimola-e-devora-as-criticas,1114265. Acesso em 30 de dezembro de 2015

BERND, Zilá. O elogio da criolidade. In: ABDALA JÚNIOR, Benjamim. (Org.). Margens da cultura: mestiçagem, hibridismo e outras misturas. São Paulo: Boitempo, 2004. p. 99-111 
BHABHA, Homi K. O local da cultura. Belo Horizonte: UFMG, 2010.

BOURDIEU, Pierre. A Dominação Masculina. 5ed. Rio de Janeiro: Bertrand Brasil, 2007.

BUTLER, Judith. “Críticamente subversiva”. In. JIMÉNEZ, Rafael M. Mérida. Sexualidades transgresoras. Una antología de estudios queer. Barcelona: Icária editorial, 2002, p.p. 55-80.

BUTLER, Judith. Problemas de gênero: feminismo e subversão da identidade. Rio de Janeiro: Civilização Brasileira, 2010.

BUTLER, Judith. The Psychic Life of Power: theories in subjection. Stanford: Stanford University, 2007.

CARLSON, Marvin. Performance: uma introdução crítica. Belo Horizonte: UFMG, 2010.

CHAMOISEAU, Patrick; BARNABÉ, Jean; CONFIANT, Raphaël. Elogio à Criolidade. Disponível em: <http:// www.ufrgs.br/cdrom/chamoiseau/chamoiseau.pdf>. Acesso em: 04 abr. 2013.

COHEN, R.GUINSBURG, J. “Do teatro à performance: aspectos da significação da cena”. In: Diálogos sobre teatro. Org. Armando Sérgio da Silva. São Paulo: EDUSP, 1992.

FOUCAULT, Michel. Vigiar e punir: história da violência nas prisões. Petrópolis: Vozes, 2000.

GROSFOGUEL, Ramón. “Descolonizar as esquerdas ocidentalizadas: para além das esquerdas eurocêntricas rumo a uma esquerda transmoderna descolonial”. In: Revista Contemporânea, v. 2, n. 2, Florianópolis, jul.-dez. 2012, p. 337-362.

GRUNVALD, Vitor. Butler, a abjeção e seu esgotamento. In: DÍAZ-BENÍTEZ, María Elvira; FÍGARI, Carlos Eduardo. Prazeres dissidentes. Rio de Janeiro: Garamond, 2009, p. 31-68.

LEVY, Pierre. As tecnologias da inteligência: 0 futuro do pensamento na era da informática. Tradução de Carlos Irineu da Costa. São Paulo: Editora 34, 1993.

LEVY, Pierre. A inteligência coletiva: por uma antropologia do ciberespaço. 2. ed. Tradução de Luiz Paulo Rouanet. São Paulo: Loyola, 1999a.

LEVY, Pierre. Cibercultura. tradução de Carlos Irineu da Costa. São Paulo, Ed. 34, 1999 b.

PRETTO, Nelson; PINTO, Cláudio da Costa. Tecnologias e Novas Educações. Revista Brasileira de Educação, v. 11, n. 31, jan./abr. 2006.

TEDESCO, Juan Carlos (org.).Educação e novas tecnologias. Tradução de Cláudia BertnerCabucci Leite. São Paulo: Cortez; Buenos Aires: Instituto Internacional de Planejamento de La Educacion; Brasília: UNESCO, 2004.

THÜRLER, Djalma. Dzi Croquettes: a instabilidade como imperativo, o hibridismo como riqueza. In: IX Reunião de Antropologia do Mercosul. Disponível em: <http://www.ram2011.org>. Acesso em: 02 de novembro 2015. 
Recebido em: 16 de janeiro de 2016

Avaliado em: 19 de janeiro de 2016 Aceito em: 21 de janeiro de 2016
1. Pós-Doutor em Crítica Literária e Professor Adjunto da Universidade Federal da Bahia.

2. Ator, performer e Mestre em Cultura e Arte pelo Programa Multidisciplinar de Pós-Graduação em Cultura e Sociedade (UFBA). 